\title{
A Population Study of the Epidemiology of Invasive Blood Stream Infections in Hospitalised Children in Malta
}

\author{
Jessica Pace, Ruth Farrugia, David Pace \\ Department of Child and Adolescent Health, Mater Dei Hospital, Tal- Qroqq, Msida, MSD 2090, Malta
}

\section{Introduction}

- Invasive bloodstream infections are a significant cause of morbidity and mortality in children. ${ }^{1}$

- Identification of the causative pathogen is crucial in determining antibiotic susceptibility and rationalising treatment.

\section{Aim}

- To determine the incidence and epidemiology of blood stream infections in hospitalised children $>3$ months old.

\section{Methodology}

- Results of all blood cultures taken from children aged 3 months16 years hospitalised on the paediatric medical wards and the neonatal intensive care unit between 2010-2017

- Cultures taken from a central line and oncology patients were excluded

- Isolates were analysed to differentiate pathogens from contaminants.

\section{Results}

- Positive rate of blood cultures - 1.19\% (60/5,044) over an 8 year period

- Mean annual incidence of bacteraemia (mean age: 3.5 years) was 11.6/100,000 children

- Most common pathogen was Staphylococcus aureus $(\mathrm{n}=14$, $23.3 \%), 42 \%(\mathrm{n}=6)$ of which were methicillin resistant. (Fig. 1)

- This was followed by Streptococcus pnuemoniae $(\mathrm{n}=11,18.3 \%)$, Escherichia coli $(\mathrm{n}=6,10 \%)$ and Enterococcus faecalis $(\mathrm{n}=6,10 \%)$.

\section{Conclusion}

- Staphylococcus aureus is the most prevalent invasive pathogen in children $>3$ months old

- Its importance as a source of community acquired blood stream infection is increasing in contrast to the decline in the incidence of vaccine preventable invasive bacterial infections.

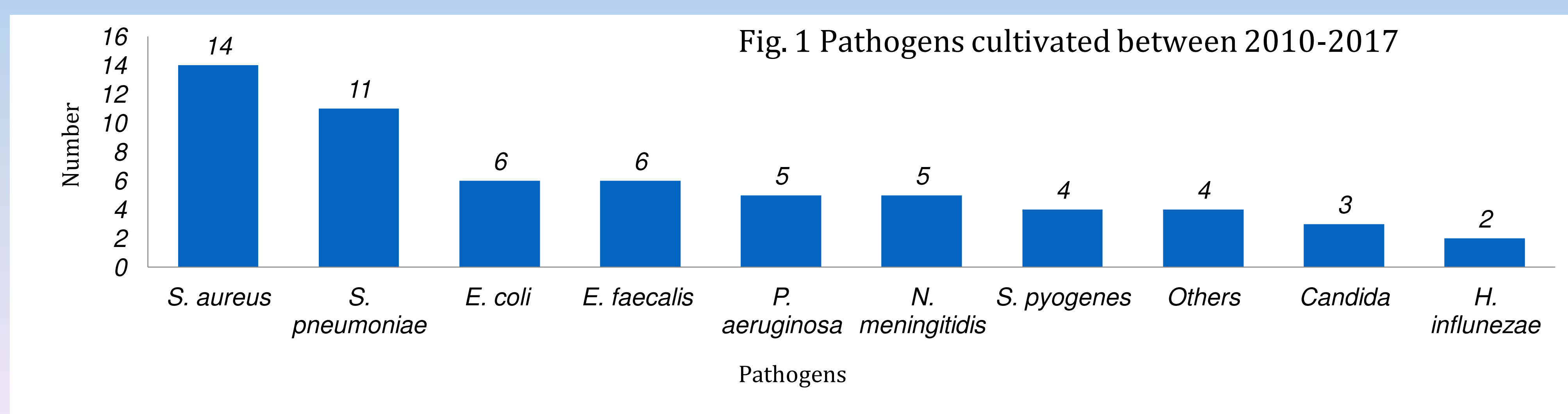

